
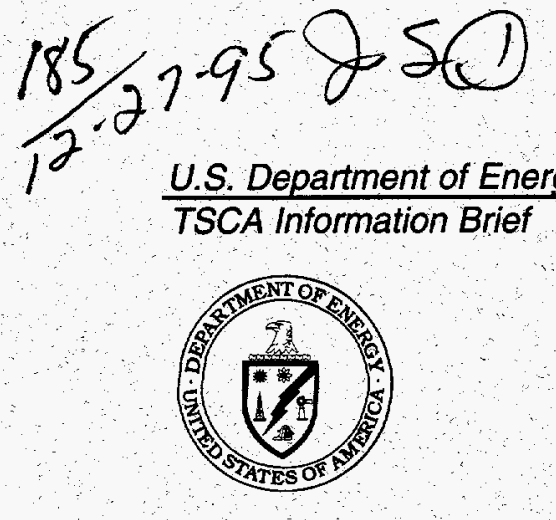

\title{
Management of PCB Laboratory Wastes
}

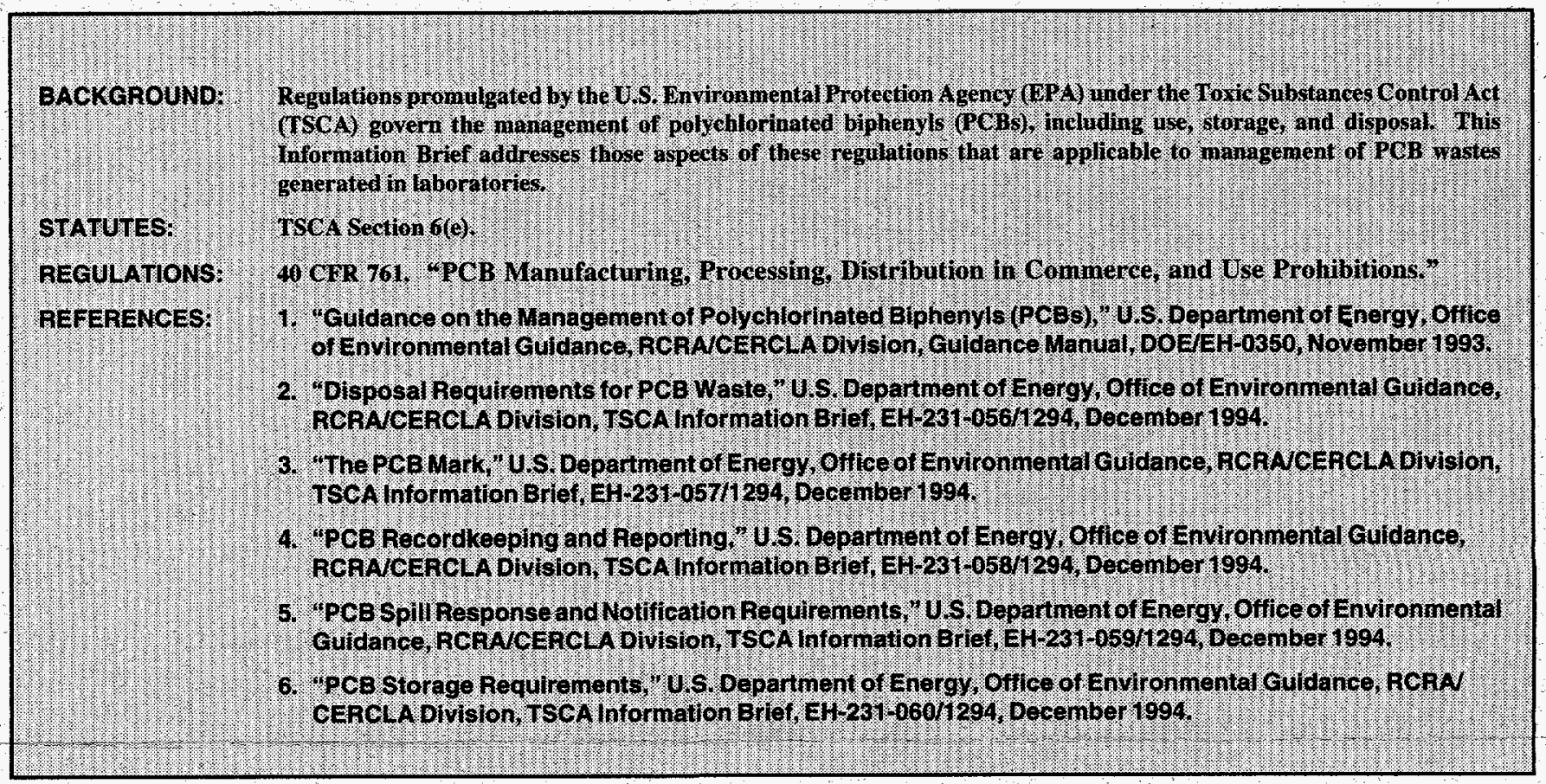

\section{In a laboratory, when are PCBs "in use" and when are they considered "wastes"?}

Under TSCA, PCBs can only be used if the use is authorized under the TSCA regulations in 40 CFR 761; otherwise, the use of $\mathrm{PCB}$ sis prohibited and the PCBs must be disposed as PCB waste (see Reference No. 2). 40 CFR $761.30(\mathrm{j})$ authorizes the use of PCBs in "small quantities for research and development." Research and development activities are defined to include activities associated with laboratory analysis.

While in the laboratory, $\mathrm{PCB}$ samples or PCB analytical standard solutions can have the status of either being in use or being wastes in storage for disposal. PCB samples/ standards are considered "in use" when they are stored prior to chemical analysis. Following analysis, PCB samples are "in use" if they are archived for enforcement or compliance purposes. If not, both excess sample material and extracted sample material are no longer considered to be "in use" and must be disposed as PCB waste. Even though extracted samples may no longer contain PCBs, they are still considered "PCB wastes" in accordance with the Anti-dilution rule (see Reference No. 2). Furthermore, any materials that contacted the PCB sample become PCB waste and must be disposed accordingly.

The following examples illustrate the Anti-dilution and contact rules:

Example 1 - An analytical standard containing PCBs at a concentration of 500 parts per million ( $\mathrm{ppm}$ ) is purchased and then diluted to make standards of lower concentrations. All of the PCB solutions developed from the $500 \mathrm{ppm}$ standard, regardless of their final concentrations, must be managed and disposed as wastes with PCB concentrations. of $500 \mathrm{ppm}$. In addition, all the glassware associated with the making and storing of these standards must be decontaminated in accordance with $\S 761.79$ or managed as PCB wastes.

Example 2-A field-generated soil sample is analytically determined to have a PCB concentration of $40 \mathrm{ppm}$. The source of the PCB in the soil is a leaking PCB Transformer ( $\geq 500$ ppm $P C B$ ). The sample container must be disposed as if it contained PCBs at a concentration of $\geq 500 \mathrm{ppm}$ or decontaminated in accordance with 40 CFR 761.79. 
Furthermore, any laboratory equipment, glassware, disposables, etc. that contacted the soil sample during sample preparation, extraction, or analysis that cannot be decontaminated in accordance with $\$ 761.79$ must also be managed as $\mathrm{PCB}$ waste and disposed in accordance with 40 CFR 761.60. [Note: EPA has proposed ehanges to these regulations which would provide additional disposal options (such as municipal solid waste landfills) for wastes with low levels of PCBs. This proposed rule is expected to be finalized in 1996.]

\section{What types of PCB wastes do laboratories generate?}

Laboratories generate excess sample waste, extracted samples, and wastes derived from analytical processing. Excess sample waste is generated when a portion of the sample remains after required amounts are extracted or diluted for analysis. For solid samples, an additional source of sample waste results from the portion of the sample that is used to determine moisture content. The extracted samples must also be managed as PCB waste even though no detectable PCBs may remain (the Anti-dilution rule applies).

PCB analytical processing wastes include but are not limited to: disposable items (such as pipettes, gloves, kimwipes, weighing dishes, and filters); glassware and/or glassware rinsates, excess and expired analytical standards; extraction solvents; spent filtration media (such as florisil, alumina, sodium sulfate, and glass wool); and autosampler vials.

\section{What are the management options for PCB laboratory wastes?}

Laboratory items (including samples and other items identified above) that have come in contact with materials having a $P C B$ concentration $\geq 50 \mathrm{ppm}$ must be disposed in accordance with requirements in 40 CFR 761.60.

These items must be manifested (40 CFR 761.207) and incinerated in a TSCA-approved incinerator or disposed in a TSCA-approved chemical waste landfill. (Laboratorygenerated PCB wastes contaminated with organic solvents and/or excess sample materials may also be subject to regulation under RCRA.)

Non-disposable glassware, which are considered containers, (e.g., beakers and flasks) can be decontaminated and reused in accordance with 40 CFR 761.79. The laboratory decontamination procedure includes triple rinsing and collecting the resulting rinsates. As mentioned above, the rinsate must be disposed in accordance with 40 CFR 761.60 if they contacted materials with a PCB concentration $\geq 50 \mathrm{ppm}$.

\section{What storage requirements are applicable to PCB laboratory wastes?}

Portions of PCB samples that are archived for enforcement or compliance purposes are not subject to storage requirements for $\mathrm{PCB}$ wastes because they are considered to be in use.

PCB solid wastes and liquid wastes with PCB concentrations between 50 and 500 ppm may be stored for up to 30 days in areas that do not meet the requirements of 40 CFR 761.65(b) (see Reference No. 6). However, the following requirements do apply to the storage of these wastes:

- The storage location must be marked in accordance with labeling requirements in 40 CFR 761.40 (see Reference No. 3.)

- Each container must be marked with the date on which the first item was placed in the container:

- Items must not be leaking or they must be overpacked with sufficient sorbent material.

- Liquid waste must be marked with a reference to the facility Spill Prevention, Control, and Countermeasures Plan provisions applicable to liquid storage locations (see p.7-30 of Reference No. 1).

Storage of PCB wastes for more than 30 days and storage of liquid wastes containing $>500 \mathrm{ppm} P C B$ s require that the: (1) storage facility meet the physical requirements specified in 40 CFR 761.65(b); (2) storage area be inspected at least once every 30 days; (3) containers be marked with the appropriate label and the date the first item in each container was placed in storage; (4) storage area and access points be clearly marked with the appropriate label; and (5) facility keep records in accordance with 40 CFR 761.180 (see Reference No. 4).

If a DOE laboratory receives samples from sources other than DOE facilities, the laboratory is considered a commercial storer unless the facility's storage of PCB waste at no time exceeds 500 liquid gallons of $\mathrm{PCB}$ waste. However, regulations applicable to commercial storage facilities (40 CFR 761.65(i)) conditionally exempt laboratories from requirements for notification and approval as long as the laboratories hold samples for disposal in areas meeting the requirements of 40 CFR $761.65(\mathrm{~b})$. 


\section{What are the marking/labelling requirements for PCB wastes?}

Laboratories must comply with regulations in $40 \mathrm{CFR}$ 761.40 regarding marking and 40 CFR 761.45 regarding label formats (see Reference No. 3). The table below matches laboratory items and laboratory areas with the label formats specified in 40 CFR 761.45 .

\section{Do laboratories have to notify EPA regarding PCB activity?}

If a DOE laboratory is an operational unit of a larger DOE site (i.e., not a "stand alone" DOE entity), the laboratory does not have to notify EPA of PCB activity as long as the site had already received a facility PCB ID number, as described in 40 CFR 761.205 .

However, if the laboratory is a stand-alone facility, 40 CFR 761.205 requires the laboratory (as a generator and/or commercial storer) to notify EPA of PCB waste activities by filing EPA Form 7710-53. Once notified of PCB waste activities, EPA assigns an EPA identification (ID) number to the laboratory. If a laboratory (generator and/or commercial storer) has previously notified EPA (or the appropriate State agency) under RCRA and has been assigned a RCRA ID number, the number should be reported on the 7710-53 form. EPA will authorize use of this same ID number for PCB waste activity.

\section{What are the manifesting requirements for $\mathrm{PCB}$ laboratory wastes?}

If the PCB concentration in sample wastes is greater than or equal to $50 \mathrm{ppm}$, the wastes must be disposed in accordance with applicable regulations. The laboratory must either manifest the waste to a commercial storer or disposer, or return the sample to the original generator. If sample wastes are sent to a commercial storer or disposer, the laboratory must: (1) manifest the waste in accordance with 40 CFR 761.208; (2) retain a copy of each manifest, as required by 40 CFR 761.209; and (3) follow the exception reporting requirements in 40 CFR 761.215 .

If the laboratory returns the samples to the original generator(s), 40 CFR 761.65(i)(2) exempts the samples from manifesting requirements as long as the laboratory ships the samples in accordance with requirements in 40 CFR 761.65(i)(3). These requirements include:

- Compliance with applicable shipping requirements (U.S. Department of Transportation requirements in 49 CFR 173.345, or U.S. Postal Regulations 652.2 and 652.3 );

- Supplying the following information to accompany the sample(s): the original generator's and laboratory's names, mailing addresses, and telephone numbers; quantity of the sample; date of sample shipment; and description of the sample; and,

- Packaging the sample so that it does not leak, spill, or vaporize during transport.

\section{Table of Marking Requirements for PCB Laboratory Wastes}

\begin{tabular}{|c|c|}
\hline PCB Item or Laboratory Area & Label Format \\
\hline All storage-for-disposal areas & $\mathrm{M}_{\mathrm{L}}$ \\
\hline Sample containers with regulated PCB concentrations $(\geq 50 \mathrm{ppm})$ & $\mathrm{M}_{\mathrm{L}}$ or $\mathrm{M}_{\mathrm{S}}$ \\
\hline All flasks and vials used to store analytical standards & $\mathrm{M}_{\mathrm{L}}$ or $\mathrm{M}_{\mathrm{S}}$ \\
\hline Cold rooms and refrigerators that store PCB Items & $\mathrm{M}_{\mathrm{L}}$ \\
\hline Waste containers & $\mathrm{M}_{\mathrm{L}}$ \\
\hline Access points to PCB analytical areas & $\mathrm{M}_{\mathrm{L}}$ \\
\hline (e.g., organic extraction, GC or GC/MS laboratory) & \\
\hline
\end{tabular}




\section{What PCB recordkeeping and reporting requirements are applicable to DOE laboratories?}

If a DOE laboratory is an operational unit of a larger DOE site (i.e., not a "stand alone" DOE entity), the laboratory would not have to maintain separate records on its PCB equipment or waste activity. Although not required, if a DOE laboratory orders PCB analytical standards, the laboratory should maintain a copy of the vendor's authorization to distribute PCBs in commerce. This documents that the laboratory acquired the standards in accordance with 40 CFR 761.30

DOE laboratories that are stand-alone facilities may have to comply with requirements in 40 CFR 761.180(a) to maintain annual records and an annual document $\log$ (see Reference No. 4). These requirements would apply to laboratories that use or store, at any one time, at least 45 kilograms ( 99.4 pounds) of PCBs in containers (i.e., flasks, vials, samples, or drums) and/or equipment (i.e., transformers, capacitors, etc.). The 45 kilogram amount includes all PCB liquids and solids generated as a result of the Antidilution rule.

All laboratories that qualify as commercial storers must keep annual records and document logs, in accordance with
40 CFR 180(a). In addition, they must submit an annual report to EPA summarizing PCB inventories and disposal activities [40 CFR 761.180(b)] and retain all documents, correspondence, and data transmitted between the owner/ operator and any State or local government pertaining to the storage or disposal of PCBs and PCB Items [40 CFR $761.180(\mathrm{f})]$.

In keeping with other PCB regulatory requirements pertaining to disposal, all stand-alone laboratories must retain copies of manifests (40 CFR 761.209); manifest discrepancy reports (40CFR 761.210); unmanifested waste reports (40 CFR 761.211); exception reports (40 CFR 761.215); and, certificates of disposal (40 CFR 761.218).

Questions of policy or questions requiring polley decisions will not be addressed in EH-413 Information Briets unless that pollcy has already been established through appropriate documentation. Please refer any questions concerning the material covered in this Intormation Brief to Carolyn Thompson Walder, EH-413, (202) 586-8248.

Post Office, if unable to deliver please return to:

Reisa Kall (EH-413)

U.S. Department of Energy

1000 Independence Ave., S.W.

Washington, D.C. 20585

\section{ADDRESS CORRECTION REQUESTED}




\section{DISCLAMMER}

Portions of this document may be illegible in electronic image produets. Images are produced from the best available original document. 